Check for updates

Cite this: RSC Adv., 2018, 8, 6667

\title{
The behavior of the aluminum trimer when combining with different superatom clusters $\uparrow$
}

\begin{abstract}
Hui Yang, ${ }^{\text {ab }}$ Di Wu, (D) ${ }^{a}$ Hui-Min He, ${ }^{a}$ Dan Yu, ${ }^{a}$ Ying Li (D) *a and Zhi-Ru Li ${ }^{a}$
The interaction between the aluminum trimer and representative (super)halogens $X\left(X=F, \mathrm{LiF}_{2}, \mathrm{BeF}_{3}, \mathrm{BF}_{4}\right)$ and (super)alkalis $\mathrm{M}\left(\mathrm{M}=\mathrm{Li}, \mathrm{FLi}_{2}, \mathrm{OLi}_{3}, \mathrm{NLi}_{4}\right)$ has been theoretically investigated at the MP2/6-311+(3df) level. Various geometrical structures were obtained for the resulting $\mathrm{Al}_{3}-\mathrm{X}$ and $\mathrm{Al}_{3}-\mathrm{M}$ superatom compounds, respectively. Natural bond orbital analysis reveals that the $\mathrm{Al}_{3}$ moiety exists in a cationic state in $\mathrm{Al}_{3}-\mathrm{X}$ while in an anionic state in $\mathrm{Al}_{3}-\mathrm{M}$ compounds. And the charge transfer between $\mathrm{Al}_{3}$ and (super)atoms is found to be enhanced in either polar or nonpolar solvent. The studied superatom compounds feature large bond energies, binding energies, and HOMO-LUMO gaps, which not only reflect their stability but indicate strong interactions between $\mathrm{Al}_{3}$ and (super)atoms. Although the solvent effect is not significant for the stability of $\mathrm{Al}_{3}-\mathrm{X}$, the $\mathrm{Al}_{3}$-superalkali compounds can be better stabilized in the presence of solvent molecules. In addition, these superatom compounds exhibit aromaticity both in the gas phase and in solution.
\end{abstract}

Received 28th November 2017 Accepted 5th February 2018

DOI: 10.1039/c7ra12852e

rsc.li/rsc-advances

unique clusters possessing ionization potentials (IPs) lower

\section{Introduction}

Clusters are extensively studied in physics because they represent the transition states between single atoms and bulk solid. ${ }^{1-8}$ On the one hand, clusters possess properties that are neither atomic-like nor solid-like but depend on their composition, size, geometry, charge state, etc. On the other hand, stable clusters can serve as basic building blocks in chemistry. ${ }^{9}$ Hence, the research of clusters is also of significance in developing novel cluster-assembled materials with tunable properties.

One of the most exciting developments in the research area of clusters is the realization that specific clusters exhibit similar chemical behavior to atoms in the periodic table. Such clusters are consequently termed superatoms. ${ }^{10-13}$ Two well-known subsets of superatoms are superhalogens ${ }^{14-17}$ and superalkalis, ${ }^{18-21}$ which have been extensively studied for more than 30 years. Superhalogens have higher electron affinities (EAs) than atomic EA limit $(\mathrm{Cl}: 3.617 \mathrm{eV})^{22}$ while superalkalis are

${ }^{a}$ Laboratory of Theoretical and Computational Chemistry, Institute of Theoretical Chemistry, Jilin University, Changchun 130023, P. R. China. E-mail: liyingedu@jlu. edu.cn

${ }^{b}$ School of Chemistry and Chemical Engineering, Shanxi Datong University, Datong 037009, P. R. China

$\dagger$ Electronic supplementary information (ESI) available: The valence molecular orbitals of IIfs, optimized structures and the corresponding physicochemical properties of the $\mathrm{Al}_{3}-\mathrm{BF}_{4}$ (4ps) and $\mathrm{Al}_{3}-\mathrm{NLi}_{4}$ (IV-24) compounds in the presence of solvents, The characteristic vibration mode of the (a) $\mathrm{Al}_{3}-\mathrm{BF}_{4}$ (4ps) and (b) $\mathrm{Al}_{3}-\mathrm{NLi}_{4}$ (IV-24) compounds in solvents and gas phase, electron-shell structures of $\mathrm{Al}_{3}{ }^{+}$and $\mathrm{Al}_{3}{ }^{-}$ions, and the hardness $\left(\eta\right.$, in eV) of the most stable $\mathrm{Al}_{3}-\mathrm{X}$ and $\mathrm{Al}_{3}-\mathrm{M}$ compounds, locations of the maximum negative NICS values, Cartesian coordinates and electronic states for the $\mathrm{Al}_{3}-\mathrm{X}$ and $\mathrm{Al}_{3}-\mathrm{M}$ compounds. See DOI: 10.1039/c7ra12852e than those of alkali atoms $(5.39-3.89 \mathrm{eV}) .{ }^{23}$ Lately, the idea of combining superalkali with superhalogen clusters has been theoretically proposed and the generated superatom compounds include $\mathrm{Al}_{13} \mathrm{~K}_{3} \mathrm{O}$ and $\mathrm{Al}_{13} \mathrm{Na}_{3} \mathrm{O},{ }^{24} \mathrm{BF}_{4}-\mathrm{M}(\mathrm{M}=\mathrm{Li}$, $\left.\mathrm{FLi}_{2}, \mathrm{OLi}_{3}, \mathrm{NLi}_{4}\right),{ }^{25} \mathrm{BLi}_{6}-\mathrm{X}\left(\mathrm{X}=\mathrm{F}, \mathrm{LiF}_{2}, \mathrm{BeF}_{3}, \mathrm{BF}_{4}\right),{ }^{26}$ and $\mathrm{Li}_{3} \mathrm{O}-\mathrm{X}$ $\left(\mathrm{X}=\mathrm{BF}_{4}, \mathrm{BeF}_{3}, \mathrm{NO}_{3}\right),{ }^{27}$ etc. It has been found that both superhalogens and superalkalis play the role of building block in the resulting ionic compounds that are named as "supersalts" by Jena et $a l^{27}$ These inspiring results motivate us to think about the following questions: can superatoms combine with other clusters, especially metal clusters? If so, what are the preferred structures as well as bonding nature of such superatom compounds? Will the structural and electronic integrity of the metal cluster break when it interacts with superatoms? How does the metal cluster behave when combining with superalkalis and superhalogens, respectively?

During the last two decades, aluminum clusters have become a rich area of research in cluster physics and chemistry. In addition to providing a basic understanding of sizedependent physical and chemical properties of simple metal clusters, researches also bring out some special characteristics of aluminum clusters. These include the potentially multivalent character of the bonding in aluminum clusters, the free electron character of aluminum which makes aluminum clusters an archetypal example of the shell model, all-metal aromaticity found in small Al-based clusters, for example, $\mathrm{Al}_{3}{ }^{-}, \mathrm{Al}_{4}{ }^{2-}$, and $\mathrm{Al}_{6}{ }^{2-}$, etc. ${ }^{28-34}$ Besides, some pure or doped aluminum clusters, such as $\mathrm{Al}_{13},{ }^{35} \mathrm{Al}_{14},{ }^{36} \mathrm{Al}_{7}{ }^{-, 37} \mathrm{Al}_{12} \mathrm{Be},{ }^{38} \mathrm{Al}_{12} \mathrm{Cu},{ }^{39}$ have been proven to show superatom features. Furthermore, small aluminum clusters share some properties in common with the more electronically complex transition metal clusters. Thus, the 
studies of p-block aluminum clusters are good complements to those of the less computationally tractable d-block metal clusters. ${ }^{40}$

As one of the smallest and thus most foundational components of aluminum clusters, aluminum trimer has been extensively studied and its electronic and geometrical structures are well understood. ${ }^{\mathbf{3 0 4 1 - 4 4}}$ Hence, it has been chosen in our work as a representative metal cluster to interact with differently shaped (super)halogens $\mathrm{X}\left(\mathrm{X}=\mathrm{F}, \mathrm{LiF}_{2}, \mathrm{BeF}_{3}, \mathrm{BF}_{4}\right)$ and (super)alkalis $\mathrm{M}$ $\left(\mathrm{M}=\mathrm{Li}, \mathrm{FLi}_{2}, \mathrm{OLi}_{3}, \mathrm{NLi}_{4}\right)$. The main objectives of this contribution are (1) to reveal different behaviors of $\mathrm{Al}_{3}$ when combining with different (super)atoms, (2) to examine stability of the resulting $\mathrm{Al}_{3}-\mathrm{X}$ and $\mathrm{Al}_{3}-\mathrm{M}$ compounds both in gas phase and in solution. Besides, aromaticity of these superatom compounds is analyzed as well. We hope that the results we provide in this work can further enrich our knowledge on superatoms and the principles obtained may work well for a variety of superatom compounds involving metal cluster building blocks, especially the $\mathrm{Al}_{n}$ group.

\section{Computational details}

The minima on the potential-energy surfaces of the $\mathrm{Al}_{3}-\mathrm{X}(\mathrm{X}=$ $\left.\mathrm{F}, \mathrm{LiF}_{2}, \mathrm{BeF}_{3}, \mathrm{BF}_{4}\right)$ and $\mathrm{Al}_{3}-\mathrm{M}\left(\mathrm{M}=\mathrm{Li}, \mathrm{FLi}_{2}, \mathrm{OLi}_{3}, \mathrm{NLi}_{4}\right)$ compounds were explored by using two approaches. The first one is to construct initial geometries artificially by considering all the possible bonding orientations between $\mathrm{Al}_{3}$ cluster and (super)atoms $\mathrm{X} / \mathrm{M}$. The second one employs a random search procedure, ${ }^{38,45-47}$ in which structures were generated by randomly distributing all atoms inside a sphere with radius $R=$ 5.0 A. The resulting geometries were optimized at the B3LYP/3$21 \mathrm{G}$ level automatically. Then, all the geometries obtained by the first method and the minimum structures from the second method were optimized using the second order Møller-Plesset (MP2) method ${ }^{48}$ with the $6-311+G(3 d f)$ basis set, followed by vibrational frequency calculations. Note that only those minimum structures where the $\mathrm{Al}_{3}$ and superatom subunits retain their respective integrity are discussed in the present work since the interaction between $\mathrm{Al}_{3}$ and superatom clusters is the focus of our attention. Natural bond orbital $(\mathrm{NBO})^{\mathbf{4 9}}$ and atom in molecules (AIM) $)^{50,51}$ analyses were performed at the same level. The nucleus-independent chemical shifts (NICS) ${ }^{52}$ values were obtained employing the GIAO-B3LYP/6-311+G(3df) method. ${ }^{53}$

The intramolecular interaction energies $\left(E_{\text {int }}\right)$ between $\mathrm{Al}_{3}$ and $\mathrm{X} / \mathrm{M}$ subunits and binding energy per atom $\left(E_{\mathrm{a}}\right)$ for these $\mathrm{Al}_{3}-\mathrm{X}$ and $\mathrm{Al}_{3}-\mathrm{M}$ species were calculated at the higher $\operatorname{CCSD}(\mathrm{T}) / /$ MP2/6-311+G(3df) level based on the MP2 geometries. ${ }^{25,38} \mathrm{We}$ used the counterpoise (CP) procedure ${ }^{54}$ to eliminate the basis set superposition error (BSSE) effect given by eqn (1): ${ }^{55}$

$$
E_{\text {int }}=E_{\mathrm{AB}}\left(X_{\mathrm{AB}}\right)-E_{\mathrm{A}}\left(X_{\mathrm{AB}}\right)-E_{\mathrm{B}}\left(X_{\mathrm{AB}}\right)
$$

where the same basis set, $X_{\mathrm{AB}}$, was used for the subunit energy $\left(E_{\mathrm{A}}\right.$ and $\left.E_{\mathrm{B}}\right)$ calculation as for the complex energy $\left(E_{\mathrm{AB}}\right)$ calculation.
All calculations were performed using the GAUSSIAN 09 program package. ${ }^{56}$ The plots of molecular configurations and orbitals were generated by the GaussView program. ${ }^{57}$

\section{Results and discussion}

\subsection{Geometrical structures}

3.1.1. $\mathbf{A l}_{3}-\mathbf{X}$. Eleven equilibrium structures with real frequencies were gained for the $\mathrm{Al}_{3}-\mathrm{X}$ compounds. The optimized geometries of $\mathrm{Al}_{3}-\mathrm{X}$ and their ionic components are displayed in Fig. 1, and their corresponding lowest vibrational frequencies are listed in Table 1.

Different from linear diatomic molecules, the $\mathrm{Al}_{3}-\mathrm{X}$ compounds have a variety of structures (see Fig. 1). The eleven $\mathrm{Al}_{3}-\mathrm{X}$ structures can be classified into five types according to the relative orientation (bonding pattern) between $\mathrm{Al}_{3}$ and $\mathrm{X}$, namely, point-to-point (pp), point-to-side (ps), side-to-point (sp), side-to-side (ss), and face-to-face (ff). Thereby the nomenclature employed for an $\mathrm{Al}_{3}-\mathrm{X}$ isomer designates the number of $\mathrm{F}$ atoms in Arabic numerals, followed by the bonding pattern. For example, 3 ss represents an $\mathrm{Al}_{3}-\mathrm{BeF}_{3}$ structure with side-toside bonding pattern.

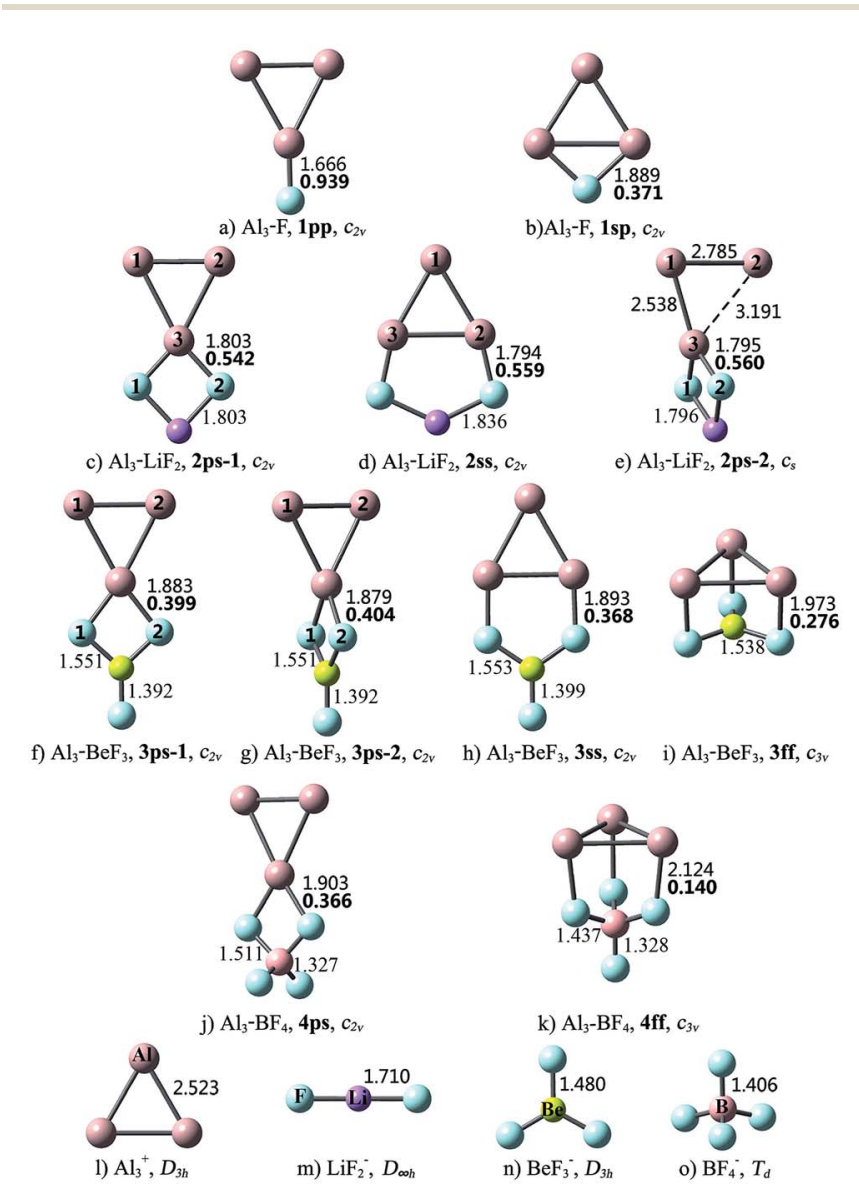

Fig. 1 Optimized structures of the $\mathrm{Al}_{3}-\mathrm{X}$ compounds and $\mathrm{Al}_{3}{ }^{+}, \mathrm{LiF}_{2}{ }^{-}$, $\mathrm{BeF}_{3}{ }^{-}, \mathrm{BF}_{4}{ }^{-}$ions at the MP2/6-311+G(3df) level, bond lengths $(\AA)$ and Laplacian of the electron density at a bond critical point $\nabla^{2} \rho(r)$ (in au., bold font) for the $\mathrm{Al}-\mathrm{F}$ bonds that connect $\mathrm{Al}_{3}$ and $\mathrm{X}$ subunits. 
Table 1 Relative energies $E_{\text {rel }}\left(\mathrm{kcal} \mathrm{mol}^{-1}\right)$, the lowest vibrational frequency $\nu_{1}\left(\mathrm{~cm}^{-1}\right), \mathrm{NBO}$ charge on the $\mathrm{Al} l_{3}$ subunit $\left(Q^{\mathrm{Al}} \mathrm{z}_{3},|e|\right), \mathrm{HOMO}-\mathrm{LUMO}$ gaps $(\mathrm{eV})$, binding energy per atom $E_{\mathrm{a}}\left(\mathrm{kcal} \mathrm{mol}^{-1}\right)$, bond energies $E_{\mathrm{b}}\left(\mathrm{kcal} \mathrm{mol}^{-1}\right)$, and the maximum negative NICS values of the $\mathrm{Al}_{3}-\mathrm{X}$ compounds (NICS max $_{\text {, ppm) }}$

\begin{tabular}{|c|c|c|c|c|c|c|c|c|c|}
\hline Species & & Orientation & $E_{\text {rel }}$ & $\nu_{1}$ & $Q^{\mathrm{Al}_{3}}$ & Gap & $E_{\mathrm{a}}$ & $E_{\mathrm{b}}$ & NICS $_{\text {max }}$ \\
\hline \multirow[t]{2}{*}{$\mathrm{Al}_{3}-\mathrm{F}$} & $1 p p$ & Point-to-point & 0.00 & 126 & 0.777 & 5.55 & 55.54 & 137.1 & -28.5 \\
\hline & $1 \mathrm{sp}$ & Side-to-point & 23.03 & 174 & 0.818 & 4.80 & 51.17 & 120.1 & -23.9 \\
\hline \multirow[t]{3}{*}{$\mathrm{Al}_{3}-\mathrm{LiF}_{2}$} & $2 p s-1$ & Point-to-side & 0.00 & 49 & 0.685 & 4.97 & 68.55 & 178.8 & -27.5 \\
\hline & $2 \mathrm{ss}$ & Side-to-side & 64.32 & 54 & 0.699 & 5.37 & 68.32 & 190.5 & -37.6 \\
\hline & 2ps-2 & Point-to-side & 84.34 & 29 & 0.685 & 4.53 & 66.05 & 174.7 & - \\
\hline \multirow[t]{4}{*}{$\mathrm{Al}_{3}-\mathrm{BeF}_{3}$} & $3 p s-1$ & Point-to-side & 0.00 & 50 & 0.748 & 5.66 & 79.47 & 168.2 & -30.6 \\
\hline & $3 p s-2$ & Point-to-side & 2.61 & 39 & 0.756 & 5.40 & 78.99 & 164.6 & -24.4 \\
\hline & $3 s s$ & Side-to-side & 9.07 & 41 & 0.768 & 5.47 & 78.45 & 169.4 & -32.0 \\
\hline & $3 \mathrm{ff}$ & Face-to-face & 12.51 & 134 & 1.375 & 6.34 & 78.31 & 180.8 & -13.9 \\
\hline \multirow[t]{2}{*}{$\mathrm{Al}_{3}-\mathrm{BF}_{4}$} & 4ps & Point-to-side & 0.00 & 38 & 0.757 & 5.68 & 86.87 & 166.4 & -30.8 \\
\hline & $4 \mathrm{ff}$ & Face-to-face & 19.99 & 89 & 0.824 & 5.64 & 85.38 & 166.7 & -12.5 \\
\hline
\end{tabular}

As shown in Fig. 1, the structural integrity of superhalogens $\mathrm{X}$ is maintained in all the $\mathrm{Al}_{3}-\mathrm{X}$ compounds. For $\mathrm{Al}_{3}-\mathrm{F}$, the $\mathrm{F}$ atom is either bound to an apex $\mathrm{Al}$ atom (1pp), or side-on bound to the $\mathrm{Al}_{3}$ triangle (1sp). From Table 1, the former is $23.03 \mathrm{kcal} \mathrm{mol}^{-1}$ more stable than the latter. There are two kinds of interaction orientations between $\mathrm{Al}_{3}$ and $\mathrm{LiF}_{2}$, namely, point-to-side (2ps-1 and 2ps-2) and side-to-side (2ss). From Fig. 1, the relative position between $\mathrm{Al}_{3}$ and $\mathrm{LiF}_{2}$ units in isomer 2ps-1 is different from that in 2ps-2. To be specific, line $\mathrm{Al}_{1} \mathrm{Al}_{2}$ is parallel to line $F_{1} F_{2}$ in 2ps-1, but is perpendicular to line $F_{1} F_{2}$ in 2ps-2. The $\mathrm{Al}_{3}-\mathrm{Li}$ distances are 2.629, 2.850 and $2.610 \AA$ for the 2ps-1, 2ss and 2ps-2 structures, respectively. Note that these lengths are close to those of $\mathrm{Al}_{3}-\mathrm{Li}$ (2.854 and $2.653 \AA$ for Ifp and Ipp, respectively), so there might also be Al-Li connections between $\mathrm{Al}_{3}$ and $\mathrm{LiF}_{2}$ units. The stability sequence is $\mathbf{2 p s - 1}>\mathbf{2 s s}$ $>$ 2ps-2 for the three $\mathrm{Al}_{3}-\mathrm{LiF}_{2}$ structures in accordance to the total energy order. Four isomers were found for the $\mathrm{Al}_{3}-\mathrm{BeF}_{3}$ compound. From Table 1, the point-to-side orientation (3ps-1, 3ps-2) is superior to the side-to-side orientation (3ss), and the least favorable structure is $\mathbf{3} \mathbf{f f}$ with the face-to-face orientation. Herein, the bonding pattern in 3ps-1 is similar to that in 2ps-1. It is worth to mention that, though 3ps-2 exhibits a similar bonding pattern to that for 2ps-2, the former has a higher symmetry $\left(C_{2 \mathrm{v}}\right)$ than the latter $\left(C_{\mathrm{s}}\right)$. The Al-Be distance of 2.460 $\AA$ for $\mathbf{3 f f}$ is close to that for the pyramidal $\mathrm{Al}_{3} \mathrm{Be}$ cluster $(2.370$ $\AA),{ }^{58}$ hence structure $\mathbf{3 f f}$ can also be regarded as three $\mathrm{F}$ atoms side-on attached to an $\mathrm{Al}_{3} \mathrm{Be}$ unit. As to $\mathrm{Al}_{3}-\mathrm{BF}_{4}$, two structures were obtained with point-to-side (4ps) and face-to-face (4ff) bonding patterns, respectively. Isomer $4 \mathbf{f f}$ is $19.99 \mathrm{kcal} \mathrm{mol}^{-1}$ less stable than isomer 4ps.

According to the above results, when $\mathrm{Al}_{3}$ interacts with superhalogens, the preferred sequence of interaction site is apex $\mathrm{Al}$ atom $>\mathrm{Al}-\mathrm{Al}$ side $>\mathrm{Al}_{3}$ ring plane, for the $\mathrm{Al}_{3}$ cluster. $\mathrm{As}$ to superhalogens, the $\mathrm{F}-\mathrm{F}$ side is superior to the plane consisting of three $\mathrm{F}$ atoms. Therefore, the most beneficial bonding pattern for the $\mathrm{Al}_{3}-\mathrm{X}$ systems is point-to-side, while the least favorable one is face-to-face. The only exception is that 2 ps-2 is $20.02 \mathrm{kcal} \mathrm{mol}^{-1}$ less stable than isomer $2 \mathrm{ss}$, which may be attributed to the evidently distorted $\mathrm{Al}_{3}$ triangle in the former. In contrast, the $\mathrm{Al}_{3}$ ring is almost intact in the four structural isomers of $\mathrm{Al}_{3}-\mathrm{BeF}_{3}$, hence the 3ps-1 and 3ps-2 isomers with point-to-side orientation possess lower total energy than the others (3ss, 3ff).

3.1.2. $\quad \mathbf{A l}_{3}-\mathbf{M}$. Ten minimum structures were identified for the $\mathrm{Al}_{3}$-(super)alkali compounds at the MP2/6-311+G(3df) level. The optimized geometries of $\mathrm{Al}_{3}-\mathrm{M}\left(\mathrm{M}=\mathrm{Li}, \mathrm{FLi}_{2}, \mathrm{OLi}_{3}, \mathrm{NLi}_{4}\right)$ and their ionic components are displayed in Fig. 2, and their

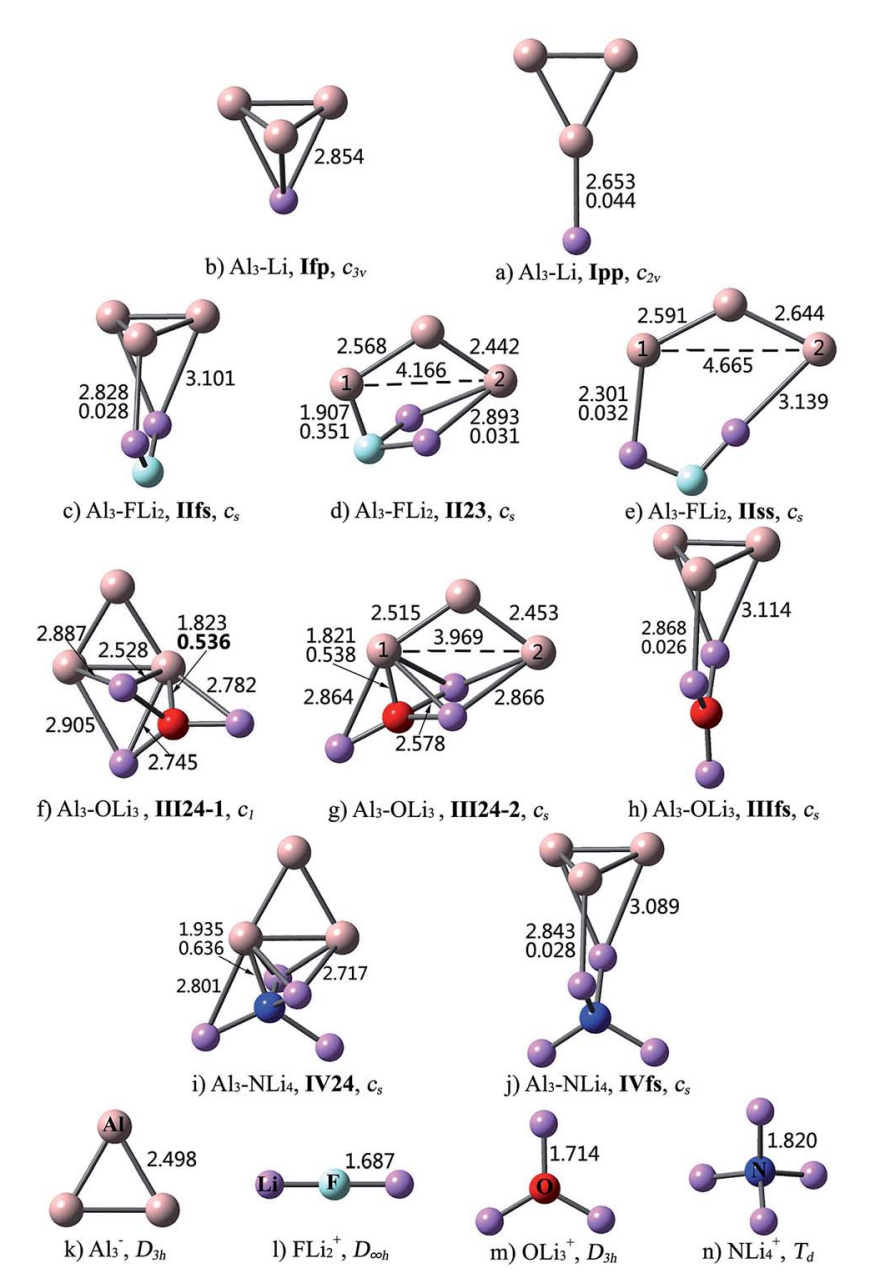

Fig. 2 Optimized structures of the $\mathrm{Al}_{3}-\mathrm{M}$ compounds and $\mathrm{Al}_{3}{ }^{-}, \mathrm{FLi}_{2}{ }^{+}$, $\mathrm{OLi}_{3}{ }^{+}, \mathrm{NLi}_{4}{ }^{+}$ions at the MP2/6-311+G(3df) level, bond lengths ( $\AA$ ) and Laplacian of the electron density at a bond critical point $\nabla^{2} \rho(r)$ (in au., bold font) for the bonds that connect $\mathrm{Al}_{3}$ and $\mathrm{M}$ subunits. 
corresponding lowest vibrational frequencies are listed in Table 2.

As can be seen from Fig. 2, the interaction between $\mathrm{Al}_{3}$ and superalkalis $\mathbf{M}$ is a bit complex. In some structures, the $\mathrm{Al}_{3}$ and $\mathrm{M}$ subunits are connected via $\mathrm{Al}-\mathrm{Li}$ bonds, while in the other structures, the central nonmetal atom of superalkali $\mathbf{M}$ also takes part in the intramolecular interaction and directly binds to the $\mathrm{Al}_{3}$ unit. Accordingly, the nomenclature employed for the former kind of $\mathrm{Al}_{3}-\mathrm{M}$ structures designates the number of $\mathrm{Li}$ atoms in Roman numerals, followed by the bonding pattern. Differently, for the latter kind of structures, the Roman numerals are followed by the number of atoms participating in the intramolecular interaction, from $\mathrm{Al}_{3}$ and $\mathrm{M}$, respectively. For example, IIfs represents an $\mathrm{Al}_{3}-\mathrm{FLi}_{2}$ structure with face-to-side bonding pattern, while II23 means that the interaction between $\mathrm{Al}_{3}$ and $\mathrm{FLi}_{2}$ involves two $\mathrm{Al}$ atoms, two $\mathrm{Li}$ atoms and the nonmetal $\mathrm{F}$ atom.

For $\mathrm{Al}_{3}-\mathrm{Li}$, the $\mathrm{Li}$ atom may cap the $\mathrm{Al}_{3}$ triangle (Ifp) or bind with the apex $\mathrm{Al}$ atom (Ipp). Isomer Ifp with the face-to-point bonding pattern is more stable. There are three types of interactions between $\mathrm{Al}_{3}$ and $\mathrm{FLi}_{2}$. Herein, isomer IIfs with face-toside bonding pattern is the lowest-energy structure, and isomer IIss with side-to-side bonding orientation is the least favorable one. As for isomer $\mathbf{I I 2 3}$, the $\mathrm{Al}_{3}$ and $\mathrm{FLi}_{2}$ moieties are linked together by two $\mathrm{Al}-\mathrm{Li}$ bonds and an $\mathrm{Al}-\mathrm{F}$ bond. Three structures were identified for the $\mathrm{Al}_{3}-\mathrm{OLi}_{3}$ compound. Superalkali $\mathrm{OLi}_{3}$ is bound to $\mathrm{Al}_{3}$ by three $\mathrm{Al}-\mathrm{Li}$ bonds in isomer IIIfs, where the $\mathrm{Al}_{3}$ and $\mathrm{OLi}_{3}$ planes are perpendicular to each other. In isomers III24-1 and III24-2, all the four atoms of $\mathrm{OLi}_{3}$ directly interact with the $\mathrm{Al}_{3}$ unit. From Table 2, the stability order is III24-1 > III24-2 > IIIfs. As to $\mathrm{Al}_{3}-\mathrm{NLi}_{4}$, two isomers were found and isomer IV24 is $31.05 \mathrm{kcal} \mathrm{mol}^{-1}$ more stable than IVfs. From Fig. 2, the bonding patterns in structures IV24 and IVfs are similar to those in structures III24-1 and IIIfs, respectively.

As shown in Fig. 2, intercluster fusion occurs when $\mathrm{Al}_{3}$ interacts with superalkali $\mathrm{M}$, which leads to broken $\mathrm{Al}_{3}$ ring in the II23, IIss and III24-2 structures. Nevertheless, the structural integrity of the $\mathrm{Al}_{3}$ cluster and superalkali $\mathrm{M}$ are retained in the lowest-energy structure of each $\mathrm{Al}_{3}-\mathrm{M}$ compound.

The structural features of the $\mathrm{Al}_{3}-\mathrm{M}$ compounds indicate that $\mathrm{Al}_{3}$ does not interact with superalkali $\mathrm{M}$ through the apex $\mathrm{Al}$ atom as it does in superhalogen compounds. From Fig. 2, $\mathrm{Al}_{3}$ prefers to bind with $\mathrm{M}$ through the ring plane in the $\mathrm{Al}_{3}-\mathrm{Li}$ and $\mathrm{Al}_{3}-\mathrm{FLi}_{2}$ compounds, while in the other two species, it prefers to interact with $\mathrm{M}$ through the $\mathrm{Al}-\mathrm{Al}$ edge. The isomer with more bonds between $\mathrm{Al}_{3}$ and $\mathrm{M}$ generally exhibits relatively higher stability. Take $\mathrm{Al}_{3}-\mathrm{OLi}_{3}$ as an example. The III24 isomer involving five $\mathrm{Al}-\mathrm{Li}$ bonds and an $\mathrm{Al}-\mathrm{O}$ bond is more stable than IIIfs with three Al-Li bonds. For two isomers with the same bonding mode, the one containing intact $\mathrm{Al}_{3}$ ring is more favorable. This is why III24-1 is $6.84 \mathrm{kcal} \mathrm{mol}^{-1}$ more stable than III24-2.

\subsection{Stability and bonding nature}

The HOMO-LUMO energy gap is considered to be an important index of electronic stability and chemical inertness of clusters. From Tables 1 and 2, the HOMO-LUMO gaps of the $\mathrm{Al}_{3}-\mathrm{X}$ and $\mathrm{Al}_{3}-\mathrm{M}$ compounds are comparable to each other, which are ranging from 4.53 to $6.34 \mathrm{eV}$ and from 4.08 to $5.62 \mathrm{eV}$, respectively. These gap values are considerably large compared with that of superatom compound $\mathrm{Al}_{13} \mathrm{~K}_{3} \mathrm{O}^{36}$ (1.24 eV), suggesting better stability of the studied compounds.

The global chemical hardness $(\eta),{ }^{59}$ which can be approximately obtained as follows,

$$
\eta \approx \frac{\mathrm{VIP}-\mathrm{VEA}}{2}
$$

was also calculated to measure the stability of the studied compounds. VIP and VEA in the formula represent vertical ionization potential and vertical electron affinity, respectively. Structures with large hardness are often considered to be harder, namely, less reactive and more stable. We took the lowest-energy structures of each compound as examples. Their hardness values are presented in Table S1 in ESI. $\dagger$ From the table, the $\eta$ values range from 1.959 to $2.569 \mathrm{eV}$, which are comparable to that of magic cluster $\mathrm{Al}_{6} \mathrm{Be}(2.751 \mathrm{eV}),{ }^{58}$ and consequently, indicate considerable stability of the $\mathrm{Al}_{3}-\mathrm{X}$ and $\mathrm{Al}_{3}-\mathrm{M}$ compounds.

The relative stability of compounds can also be examined by binding energy per atom $\left(E_{\mathrm{a}}\right)$, and the larger the $E_{\mathrm{a}}$ value, the better the stability. It is found that the $E_{\mathrm{a}}$ values of the $\mathrm{Al}_{3}-\mathrm{X}$ compounds show an increasing tendency with increasing atom

Table 2 Relative energies $E_{\text {rel }}\left(\mathrm{kcal} \mathrm{mol}^{-1}\right)$, the lowest vibrational frequency $\nu_{1}\left(\mathrm{~cm}^{-1}\right), \mathrm{NBO}$ charge on the $\mathrm{Al}_{3}$ subunit $\left(Q^{\mathrm{Al}},|e|\right)$, $\mathrm{HOMO}-\mathrm{LUMO}$ gaps $(\mathrm{eV})$, binding energy per atom $E_{\mathrm{a}}\left(\mathrm{kcal} \mathrm{mol}^{-1}\right)$, bond energies $E_{\mathrm{b}}\left(\mathrm{kcal} \mathrm{mol}^{-1}\right)$, and the maximum negative $\mathrm{NICS}$ values of the $\mathrm{Al}_{3}-\mathrm{M}$ compounds (NICS max, $\mathrm{ppm}$ )

\begin{tabular}{|c|c|c|c|c|c|c|c|c|c|}
\hline Species & & Orientation & $E_{\text {rel }}$ & $\nu_{1}$ & $Q^{\mathrm{Al}_{3}}$ & Gap & $E_{\mathrm{a}}$ & $E_{\mathrm{b}}$ & $\mathrm{NICS}_{\max }$ \\
\hline \multirow[t]{2}{*}{$\mathrm{Al}_{3}-\mathrm{Li}$} & Ifp & Face-to-point & 0.00 & 180 & -0.506 & 5.55 & 33.17 & 48.6 & -39.0 \\
\hline & Ipp & Point-to-point & 11.99 & 80 & -0.675 & 4.93 & 30.00 & 37.2 & -29.6 \\
\hline \multirow[t]{3}{*}{$\mathrm{Al}_{3}-\mathrm{FLi}_{2}$} & IIfs & Face-to-side & 0.00 & 63 & -0.519 & 5.62 & 52.55 & 61.7 & -35.5 \\
\hline & II23 & Side-to-face & 16.28 & 119 & -0.295 & 5.36 & 49.75 & 75.7 & -17.9 \\
\hline & IIss & Side-to-side & 35.64 & 43 & -0.422 & 4.95 & 47.84 & 58.0 & - \\
\hline \multirow[t]{3}{*}{$\mathrm{Al}_{3}-\mathrm{OLi}_{3}$} & III24-1 & Side-to-face & 0.00 & 60 & -0.266 & 4.08 & 60.71 & 92.4 & -34.8 \\
\hline & III24-2 & Side-to-face & 6.84 & 58 & -0.314 & 4.21 & 59.72 & 101.0 & -14.4 \\
\hline & IIIfs & Face-to-side & 19.50 & 49 & -0.454 & 4.91 & 58.21 & 65.5 & -36.1 \\
\hline \multirow[t]{2}{*}{$\mathrm{Al}_{3}-\mathrm{NLi}_{4}$} & IV24 & Side-to-face & 0.00 & 24 & -0.361 & 4.11 & 54.08 & 94.7 & -26.1 \\
\hline & IVfs & Face-to-side & 31.05 & 25 & -0.350 & 4.90 & 50.58 & 55.0 & -34.7 \\
\hline
\end{tabular}


number. The lowest-energy structures can be taken as examples. From Table 1 , the $E_{\mathrm{a}}$ values increase in the order $55.54 \mathrm{kcal} \mathrm{mol}{ }^{-1}\left(\mathrm{Al}_{3}-\mathrm{F}\right)<68.55 \mathrm{kcal} \mathrm{mol}^{-1}\left(\mathrm{Al}_{3}-\mathrm{LiF}_{2}\right)<$ $79.47 \mathrm{kcal} \mathrm{mol}^{-1}\left(\mathrm{Al}_{3}-\mathrm{BeF}_{3}\right)<86.87 \mathrm{kcal} \mathrm{mol}^{-1}\left(\mathrm{Al}_{3}-\mathrm{BF}_{4}\right)$. By contrast, among the $\mathrm{Al}_{3}-\mathrm{M}$ compounds, the $\mathrm{Al}_{3}-\mathrm{OLi}_{3}$ species exhibit the largest $E_{\mathrm{a}}$ values of $58.21-60.71 \mathrm{kcal} \mathrm{mol}^{-1}$. It is also noted that the $\mathrm{Al}_{3}$-superhalogen compounds possess larger $E_{\mathrm{a}}$ values than the $\mathrm{Al}_{3}$-superalkali compounds, which may reflect the superior stability of the former system.

The bond energies $E_{\mathrm{b}}$ of the $\mathrm{Al}_{3}-\mathrm{X}$ and $\mathrm{Al}_{3}-\mathrm{M}$ compounds are defined as the negative of $E_{\text {int }}$ values. A larger $E_{\mathrm{b}}$ value implies a stronger interaction between $\mathrm{Al}_{3}$ and (super)atoms. As can be seen from Table 1 , the $E_{\mathrm{b}}$ values of the $\mathrm{Al}_{3}-\mathrm{X}$ compounds are as large as 120.1-190.5 $\mathrm{kcal} \mathrm{mol}^{-1}$, which are comparable to or much larger than traditional ionic bond energy of $133.5 \mathrm{kcal} \mathrm{mol}{ }^{-1}$ for LiF and bond energies (117.5$128.45 \mathrm{kcal} \mathrm{mol}^{-1}$ ) of superatom compounds $\mathrm{Al}_{13} \mathrm{~K}_{3} \mathrm{O}^{24}$ and $\mathrm{Li}_{3} \mathrm{O}-\mathrm{X}\left(\mathrm{X}=\mathrm{BF}_{4}, \mathrm{BeF}_{3}, \mathrm{NO}_{3}\right) .{ }^{27}$ Thus, the $\mathrm{Al}_{3}$ cluster can tightly bind with (super)halogen $\mathrm{X}$. Note that the bond energy sequence is not completely consistent with the stability sequence of the isomers. For example, the total energy of 2 ps-1 is much lower than that of $2 \mathbf{s s}$, but the latter has a larger $E_{\mathrm{b}}$ value of $190.5 \mathrm{kcal} \mathrm{mol}^{-1}$. This is due to the fact that isomer $2 \mathrm{ss}$ contains one more $\mathrm{Al}-\mathrm{Li}$ bond, and consequently, shows a stronger interaction between the $\mathrm{Al}_{3}$ and $\mathrm{LiF}_{2}$ moieties. Similarly, the $\mathbf{3 f f}$ isomer with $\mathrm{Al}-\mathrm{Be}$ connections has the largest bond energy among the $\mathrm{Al}_{3}-\mathrm{BeF}_{3}$ species. For the other $\mathrm{Al}_{3}-$ superhalogen compounds without $\mathrm{Al}-$ metal atom interactions, the $E_{\mathrm{b}}$ value varies in the $164.6-169.4 \mathrm{kcal} \mathrm{mol}^{-1}$ range. From Table 2, the bond energies of 37.2-101.0 kcal mol ${ }^{-1}$ for $\mathrm{Al}_{3}-\mathrm{M}$ are smaller compared with those of the $\mathrm{Al}_{3}-\mathrm{X}$ compounds, but are large enough to guarantee the strong interaction between $\mathrm{Al}_{3}$ and (super)alkali M. Besides, those $\mathrm{Al}_{3}-\mathrm{M}$ isomers involving nonmetal-atom- $\mathrm{Al}_{3}$ connections, namely II23, III24-1, III24-2, IV24, exhibit much larger $E_{\mathrm{b}}$ values than the others.

To better understand the structures and stability of compounds assembled by $\mathrm{Al}_{3}$ cluster and (super)atoms, we explored the bonding character of the $\mathrm{Al}_{3}-\mathrm{X}$ and $\mathrm{Al}_{3}-\mathrm{M}$ compounds on the basis of NBO and AIM analyses. Based on $\mathrm{NBO}$ analysis, the $\mathrm{Al}_{3}$ unit exists in cationic state in $\mathrm{Al}_{3}-\mathrm{X}$ while in anionic state in the $\mathrm{Al}_{3}-\mathrm{M}$ compounds.

As shown in Table 1, the sum of NBO charges (0.685$0.824|e|)$ on the $\mathrm{Al}_{3}$ subunit in each $\mathrm{Al}_{3}-\mathrm{X}$ compound is close to +1 (except for isomer $\mathbf{3 f f}$ ), denoting that an electron transfers from $\mathrm{Al}_{3}$ to (super)halogen $\mathrm{X}$. This is consistent with the recent work of Zhao et al., where $\mathrm{Al}_{3}$ has been indicated to be a superalkali cluster. ${ }^{60}$ Structure $3 \mathrm{ff}$ contains an $\mathrm{Al}_{3} \mathrm{Be}$ unit, and the electron sharing between $\mathrm{Al}_{3}$ and Be results in 1.375|e| NBO charge on the $\mathrm{Al}_{3}$ subunit. Different from the case of $\mathrm{Al}_{3}-\mathrm{X}$, the $\mathrm{Al}_{3}$ subunits are negatively charged with -0.266 to $-0.675|e|$ in the $\mathrm{Al}_{3}-\mathrm{M}$ compounds. It means that the (super)alkalis are capable of reducing the $\mathrm{Al}_{3}$ cluster. To be specific, (super) alkali $\mathrm{M}$ is apt to lose an electron while the $\mathrm{Al}_{3}$ cluster longs for an electron to achieve a closed-shell configuration. To clearly show the electron-shell structure and molecular orbital characteristics of the $\mathrm{Al}_{3}-\mathbf{M}$ compounds, isomer IIfs is taken as an example and its valence molecular orbitals (MOs) are illustrated in Fig. S1. $\dagger$ From the figure, the valence molecular orbitals of IIfs can be considered originated from $\mathrm{Al}_{3}{ }^{-}$and $\mathrm{FLi}_{2}{ }^{+}$subunits, respectively. Obviously, both $\mathrm{Al}_{3}$ and $\mathrm{FLi}_{2}$ moieties obtain shellclosed electronic configurations $\left(1 \mathrm{~s}^{2} 1 \mathrm{p}^{6} 2 \mathrm{~s}^{2}\right.$ and $1 \mathrm{~s}^{2} 1 \mathrm{p}^{6}$, respectively, according to spherical jellium model ${ }^{61,62}$ ) by charge transfer. As a result, the IIfs structure achieve high stability from the $\mathrm{Al}_{3}{ }^{-}$and $\mathrm{FLi}_{2}{ }^{+}$segments, respectively. This is the same case for other $\mathrm{Al}_{3}-\mathrm{M}$ compounds.

The Laplacian of the electron density at a bond critical point (BCP), $\nabla^{2} \rho(r)$, is an important quantity based on the AIM theory for describing the chemical bonding nature. ${ }^{\mathbf{5 0 , 5 1}}$ Hence, the $\nabla^{2} \rho(r)$ values for dominant bonds that connect $\mathrm{Al}_{3}$ and $\mathrm{X} / \mathrm{M}$ subunits were calculated, and are shown in Fig. 1 and 2, respectively. From Fig. 1 , the $\nabla^{2} \rho(r)$ values of Al-F bonds vary in the range of 0.140-0.939 au., indicating that the $\mathrm{Al}_{3}$ and (super) halogen subunits are connected by ionic bonds. These present a situation akin to that of superatom compounds $\mathrm{BF}_{4}-\mathrm{M}(\mathrm{M}=$ $\left.\mathrm{Li}, \mathrm{FLi}_{2}, \mathrm{OLi}_{3}, \mathrm{NLi}_{4}\right)^{25}$ and $\mathrm{BLi}_{6}-\mathrm{X}\left(\mathrm{X}=\mathrm{F}, \mathrm{LiF}_{2}, \mathrm{BeF}_{3}, \mathrm{BF}_{4}\right){ }^{26}$ The superhalogen and superalkali clusters are also ionically bonded in these compounds, and the ionic connections possess 0.1060.361 au. $\nabla^{2} \rho(r)$ values, which are comparable to those of the $\mathrm{Al}_{3}-\mathrm{X}$ compounds.

As can be seen from Fig. 2, the combination of $\mathrm{Al}_{3}$ and (super)alkali $\mathrm{M}$ involves one or more $\mathrm{Al}-\mathrm{Li}$ metallic bonds. Besides, the $\nabla^{2} \rho(r)$ values of $0.351-0.636$ au. confirm the ionic bonding nature of the $\mathrm{Al}-\mathrm{F} / \mathrm{O} / \mathrm{N}$ bonds in the II23, III24-1, III242, IV24 structures. Note that these compounds have much larger bond energies compared with the others, suggesting that the ionic bonds contribute a lot to the interaction between $\mathrm{Al}_{3}$ and superalkali M. Similarly, ionic bonds play an important role in higher stability (namely larger binding energy and bond energy values) of $\mathrm{Al}_{3}-\mathrm{X}$ compared with the $\mathrm{Al}_{3}-\mathrm{M}$ system, since the former series are typical ionic compounds. It can be seen that both 1pp and II23 structures contain an Al-F ionic bond. Whereas, the Al-F bond in 1pp is much stronger compared with that in II23, as reflected by shorter bond length and larger $\nabla^{2} \rho(r)$ value of the former. Hence, the bond energy of 1pp is quite larger than that of II23. Besides, the preferred interaction site sequence of $\mathrm{Al}_{3}$ when interacting with superhalogens can also be explained by the strength of Al-X ionic bonds. To be specific, for each $\mathrm{Al}_{3}-\mathrm{X}$ compound, the $\mathrm{Al}-\mathrm{F}$ bond is the strongest, reflected by the shortest bond length and largest $\nabla^{2} \rho(r)$ value, when $\mathrm{Al}_{3}$ binds with superhalogens through an apex $\mathrm{Al}$ atom. The only exception is the $\mathrm{Al}_{3}-\mathrm{LiF}_{2}$ compound. Its three isomers have similar $\mathrm{Al}-\mathrm{F}$ bond lengths and corresponding $\nabla^{2} \rho(r)$ values. In contrast, the $\mathrm{Al}-\mathrm{F}$ bond is the weakest, reflected by the longest bond length and smallest $\nabla^{2} \rho(r)$ value, when $\mathrm{Al}_{3}$ interacts with superhalogens through its ring plane (see Fig. 1).

Since the aforementioned investigations were performed within the gas-phase approximation, one may wonder to what extent the calculations would be affected when solvent effects are taken into account. Besides, do $\mathrm{Al}_{3}-\mathrm{X}$ and $\mathrm{Al}_{3}-\mathrm{M}$ compounds behave differently upon including a solvent? To address these questions, we took $\mathrm{Al}_{3}-\mathrm{BF}_{4}$ (4ps) and $\mathrm{Al}_{3}-\mathrm{NLi}_{4}$ (IV-24) as examples and ran parallel calculations by employing a self-consistent reaction-field (SCRF) treatment with a polarizable continuum model (PCM). ${ }^{63,64}$ Thereby, their optimized structures were 
obtained in polar (ethanol) and nonpolar (cyclohexane) environments, respectively, and are displayed in Fig. S2. $\dagger$ The corresponding physicochemical properties of $\mathbf{4 p s}$ and IV-24 were also calculated by using the PCM model, and are listed in Table S2. $\dagger$

Compared with the optimized structures in gas-phase, all the ionic bonds that connect $\mathrm{Al}_{3}$ and superatom subunits elongate in the presence of solvents. From Fig. S2, $\dagger$ the Al-Li metallic bonds of $\mathrm{Al}_{3}-\mathrm{NLi}_{4}$ elongate in polar solvent but shorten in nonpolar solvent. Nevertheless, it can be concluded that solvent effect on the geometrical structures of superatom compounds is not significant since the $\mathbf{4 p s}$ and $\mathbf{I V - 2 4}$ structures do not change much in solution.

To explore the solvent effect on infrared (IR) spectrum of the 4ps and IV-24 isomers, their characteristic vibrations with the largest IR intensity were selected and examined with the PCM model. The stretching movement of superhalogen $\mathrm{BF}_{4}$ toward $\mathrm{Al}_{3}$ cluster is the characteristic vibration of 4 ps both in gasphase and in solution (see Fig. S3a $\dagger$ ). From Table $\mathrm{S} 2, \uparrow$ the stretching frequency is red-shifted by 28.7 and $12.8 \mathrm{~cm}^{-1}$, and the corresponding IR intensity increases 213.2 and $93.8 \mathrm{~km}$ $\mathrm{mol}^{-1}$ in the presence of polar and nonpolar solvents, respectively. As to IV-24, its characteristic vibration is the stretching mode of superalkali $\mathrm{NLi}_{4}$ relative to $\mathrm{Al}_{3}$ no matter whether in gas phase or in solution (see Fig. S3b $\dagger$ ). Meanwhile, the characteristic vibrational frequency of $\mathbf{I V - 2 4}$ also undergoes redshifts of 10.4 and $54.4 \mathrm{~cm}^{-1}$ in polar and nonpolar solvents, respectively. Moreover, it can be found that both polar and nonpolar solvents promote the charge transfer between $\mathrm{Al}_{3}$ and superatom clusters, especially superalkali $\mathrm{NLi}_{4}$. As a result, the stability of $\mathrm{Al}_{3}-$ $\mathrm{NLi}_{4}$ is enhanced a lot in the presence of solvent molecules, which is reflected by the increased HOMO-LUMO gap, $E_{\mathrm{a}}$, and $E_{\mathrm{b}}$ values. And this is particular the case when polar solvent (ethanol) is involved. For example, the bond energy of $\mathrm{Al}_{3}-\mathrm{NLi}_{4}$ reaches to $176.0 \mathrm{kcal} \mathrm{mol}^{-1}$ in ethanol environment. Note that this value is even larger than that of $\mathrm{Al}_{3}-\mathrm{BF}_{4}$. Hence, the $\mathrm{Al}_{3}-$ superalkali compounds may be better stabilized in solvents than in gas phase. As far as $\mathrm{Al}_{3}-\mathrm{BF}_{4}$ is concerned, the HOMOLUMO gap value becomes a bit larger according to the prediction of PCM solvation model. Apart from that, solvent effect hardly influences its stability.

\subsection{Aromaticity}

According to previous report, the $\mathrm{Al}_{3}{ }^{-}$anion has double aromaticity. ${ }^{30}$ From Fig. S4, $\dagger$ the $\sigma$-bonding HOMO orbital of $\mathrm{Al}_{3}{ }^{-}$renders $\sigma$-aromaticity, while the $\pi$-bonding HOMO-1 orbital renders $\pi$-aromaticity. The $\mathrm{Al}_{3}{ }^{+}$ring, by contrast, is also expected to possess $\pi$-aromaticity arising from its $\pi$-bonding HOMO orbital. Since $\mathrm{Al}_{3}{ }^{-}$and $\mathrm{Al}_{3}{ }^{+}$ions maintain their structural and electronic integrity in most $\mathrm{Al}_{3}-\mathrm{M}$ and $\mathrm{Al}_{3}-\mathrm{X}$ compounds, respectively, the resulting superatom compounds are supposed to be aromatic as well.

The nucleus-independent chemical shift (NICS), proposed by Schleyer and coworkers, is an efficient method to probe aromaticity of a molecule. Negative and positive NICS values denote aromaticity and antiaromaticity, respectively. ${ }^{52}$ To

examine the aromaticity of the studied superatom compounds, the NICS values were calculated at, above, and below the geometrical center of the $\mathrm{Al}_{3}$ subunits, ${ }^{\mathbf{5 3 , 6 5}}$ and the spatial locations of the maximum NICS values are listed in Tables S3 and $\mathrm{S} 4 . \dagger$ Because of the serious deformation of $\mathrm{Al}_{3}$ moiety in structures 2ps-2 and IIss, their aromaticity is not considered in this work. Although the $\mathrm{Al}_{3}$ moiety also undergoes severe deformation in isomers II23 and III24-2, the three $\mathrm{Al}$ atoms and two Li atoms are seen to form a metal cage which might have three-dimensional (3-D) aromaticity.

The maximum NICS values for the $\mathrm{Al}_{3}-\mathrm{X}$ and $\mathrm{Al}_{3}-\mathrm{M}$ compounds are shown in Tables 1 and 2, respectively. From the

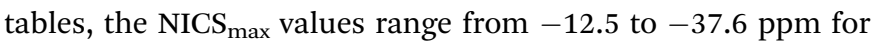
$\mathrm{Al}_{3}-\mathrm{X}$ and from -14.4 to $-39.0 \mathrm{ppm}$ for $\mathrm{Al}_{3}-\mathrm{M}$, confirming their aromatic nature. Nevertheless, it is worth noting that isomers 3ff and 4ff show considerably lower NICS $_{\max }$ values $(-13.9$ and -12.5 ppm, respectively) compared to isolated $\mathrm{Al}_{3}{ }^{+}$ring $\left(-31.4 \mathrm{ppm}\right.$ at the same computational level) and other $\mathrm{Al}_{3}-\mathrm{X}$ structures. To explore the reason behind this, isomers 4 fff and 4ps are taken as examples. Their first four valence MOs are shown in Fig. 3. From the figure, the four MOs of 4ps originate from the $\mathrm{Al}_{3}$ subunit and look like duplicates of those of isolated $\mathrm{Al}_{3}^{+}$ring. As a result, 4ps exhibits $\pi$-aromaticity and its NICS $_{\text {max }}$ value $(-30.8 \mathrm{ppm})$ is close to that of isolated $\mathrm{Al}_{3}{ }^{+}$. This is the same case for isomers 1pp, 1sp, 2ps-1, 2ss, 3ps-1, 3ps-2, and 3ss. Interestingly, the MOs of the $\mathrm{Al}_{3}$ cluster seem to have been rearranged while it interacts with superhalogen $\mathrm{BeF}_{3}$ and $\mathrm{BF}_{4}$ in the face-to-face orientation. As shown in Fig. 3, the HOMO orbital of $\mathbf{4 f f}$ turns out to be a $\sigma$-bonding orbital formed from in-plane $3 \mathrm{p}$ orbital of $\mathrm{Al}$ atoms, which renders $\sigma$-aromaticity to this structure. The same holds true for the $\mathbf{3 f f}$ isomer. Thus, the $\mathrm{Al}_{3}{ }^{+}$ring can exhibit different aromaticity depending on how it combined with superhalogen anions. Besides, the $\sigma$ aromaticity of the $\mathrm{Al}_{3}{ }^{+}$subunit corresponds to a smaller NICS value compared with its $\pi$-aromaticity. In addition, isomers II23 and III24-2 do possess 3-D aromaticity although their NICS $_{\text {max }}$ values of -17.9 and $-\mathbf{1 4 . 4} \mathrm{ppm}$, respectively, are relatively low

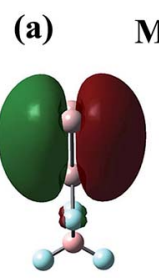

HOMO Molecular Orbitals of isomer 4ps

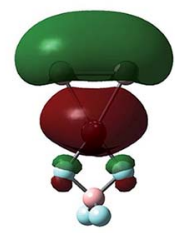

HOMO-1

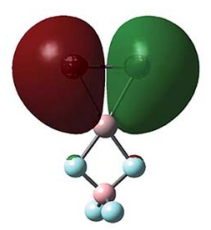

HOMO-1'

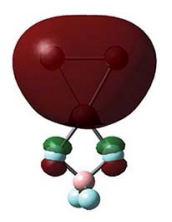

HOMO-3

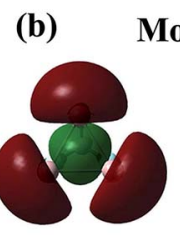

HOMO
Molecular Orbitals of isomer $4 \mathrm{ff}$

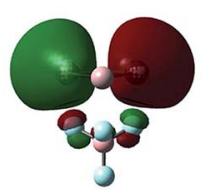

HOMO-1

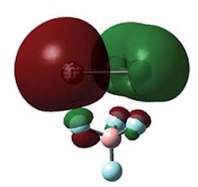

HOMO-1'

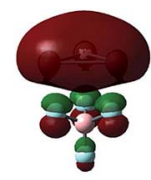

HOMO-3
Fig. 3 Valence molecular orbitals of isomers (a) $4 p s$ and (b) $4 \mathrm{ff}$. 
compared to other $\mathrm{Al}_{3}-\mathrm{M}$ compounds. Note that the aromaticity of these superatom compounds would reduce upon including solvent effect, which is reflected by decreased NICS $_{\text {max }}$ values of 4ps and IV-24 in both polar and nonpolar environments (see Table $\mathbf{S} 2 \dagger$ ). It implies that the delocalized valence electron cloud of the $\mathrm{Al}_{3}$ subunit becomes less concentrated due to the interaction with solvent molecules.

\section{Conclusions}

In summary, we have theoretically studied two types of superatom compounds by combining the $\mathrm{Al}_{3}$ trimer with different shaped (super)halogens $\mathrm{X}\left(\mathrm{X}=\mathrm{F}, \mathrm{LiF}_{2}, \mathrm{BeF}_{3}, \mathrm{BF}_{4}\right)$ or (super)alkalis $\mathrm{M}\left(\mathrm{M}=\mathrm{Li}, \mathrm{FLi}_{2}, \mathrm{OLi}_{3}, \mathrm{NLi}_{4}\right)$. NBO analysis reveals that the $\mathrm{Al}_{3}$ cluster donates electron to the former whereas gains electron from the latter species. Diverse structures have been obtained for the resulting $\mathrm{Al}_{3}-\mathrm{X}$ and $\mathrm{Al}_{3}-\mathrm{M}$ compounds. The most beneficial bonding pattern in the $\mathrm{Al}_{3}-\mathrm{X}$ systems is pointto-side, while the least favorable one is face-to-face. As for the $\mathrm{Al}_{3}-\mathrm{M}$ compounds, $\mathrm{Al}_{3}$ prefers to bind with $\mathrm{Li}$ and $\mathrm{FLi}_{2}$ through its ring plane, while prefers to interact with $\mathrm{OLi}_{3}$ and $\mathrm{NLi}_{4}$ through the $\mathrm{Al}-\mathrm{Al}$ edge. All the studied superatom compounds possess large bond energies, indicating strong interactions between $\mathrm{Al}_{3}$ and (super)atoms. Although the geometrical structures of the studied compounds do not change much when solvent effects are taken into account, the stability of $\mathrm{Al}_{3}-\mathrm{NLi}_{4}$ is obviously enhanced in the presence of solvent molecules. As expected, the $\mathrm{Al}_{3}$ ring brings aromaticity to these superatom compounds no matter whether in gas phase or in solution. What is intriguing is that the $\mathrm{Al}_{3}{ }^{+}$ring can exhibit different aromaticity ( $\pi$ or $\sigma$ aromaticity) when combined with different superhalogen anions.

\section{Conflicts of interest}

There are no conflicts of interest to declare.

\section{Acknowledgements}

This work is supported by the National Natural Science Foundation of China (Grant No. 21375017, 21603032) and State Key Development Program for Basic Research of China (Grant No. 2013CB834801).

\section{References}

1 J. Xiang, S. H. Wei, X. H. Yan, J. Q. You and Y. L. Mao, J. Chem. Phys., 2004, 120, 4251-4257.

2 Y. Li, D. Wu, Z. R. Li and C. C. Sun, J. Comput. Chem., 2007, 28, 1677-1684.

3 P. Jena, J. Phys. Chem. Lett., 2013, 4, 1432-1442.

4 Y. Negishi, W. Kurashige, Y. Niihori and K. Nobusada, Phys. Chem. Chem. Phys., 2013, 15, 18736-18751.

5 J. Y. Liu, D. Wu, W. M. Sun, Y. Li and Z. R. Li, Dalton Trans., 2014, 43, 18066-18073.

6 A. Fernando, K. D. M. Weerawardene, N. V. Karimova and C. M. Aikens, Chem. Rev., 2015, 115, 6112-6216.
7 X. Li, H. Wu, X.-B. Wang and L.-S. Wang, Phys. Rev. Lett., 1998, 81, 1909-1912.

8 T. Bergmann, H. Limberger and T. P. Martin, Phys. Rev. Lett., 1988, 60, 1767-1770.

9 S. Khanna and P. Jena, Phys. Rev. B, 1995, 51, 13705.

10 S. Khanna and P. Jena, Phys. Rev. Lett., 1992, 69, 1664.

11 V. M. Medel, J. U. Reveles, S. N. Khanna, V. Chauhan, P. Sen and A. W. Castleman, Proc. Natl. Acad. Sci. U. S. A., 2011, 108, 10062-10066.

12 V. Medel, J. U. Reveles and S. N. Khanna, J. Appl. Phys., 2012, 112, 064313-064319.

13 V. Chauhana, V. M. Medelb, J. U. Revelesb, S. N. Khannab and P. Sena, Chem. Phys. Lett., 2012, 528, 39-43.

14 I. Anusiewicz and P. Skurski, Chem. Phys. Lett., 2002, 358, 426-434.

15 S. Smuczynska and P. Skurski, Chem. Phys. Lett., 2008, 452, 44-48.

16 H. Yang, Y. Li, H.-M. He, J. Tong, D. Wu and Z.-R. Li, Chem. Phys. Lett., 2017, 684, 273-278.

17 G. L. Gutsev and A. I. Boldyrev, Chem. Phys., 1981, 56, 277283.

18 A. N. Alexandrova and A. I. Boldyrev, J. Phys. Chem. A, 2003, 107, 554-560.

19 G. L. Gutsev and A. I. Boldyrev, Chem. Phys. Lett., 1982, 92, 262-266.

20 E. Rehm, A. I. Boldyrev and P. v. R. Schleyer, Inorg. Chem., 1992, 31, 4834-4842.

21 J. Tong, Y. Li, D. Wu, Z. R. Li and X. R. Huang, J. Chem. Phys., 2009, 131, 164307.

22 H. Hotop and W. C. Lineberger, J. Phys. Chem. Ref. Data, 1985, 14, 731-750.

23 S. G. Lias, J. E. Bartmess, J. F. Liebman, J. L. Homes, R. D. Levin and W. G. Mallard, J. Phys. Chem. Ref. Data, 1988, 17(Supp1), 1285-1363.

24 A. C. Reber, S. N. Khanna and A. W. Castleman, J. Am. Chem. Soc., 2007, 129, 10189-10194.

25 H. Yang, Y. Li, D. Wu and Z.-r. Li, Int. J. Quantum Chem., 2012, 112, 770-778.

26 Y. Li, D. Wu and Z. R. Li, Inorg. Chem., 2008, 47, 9773-9778.

27 S. Giri, S. Behera and P. Jena, J. Phys. Chem. A, 2014, 118, 638-645.

28 X. Li, A. E. Kuznetsov, H. F. Zhang, A. I. Boldyrev and L. S. Wang, Science, 2001, 291, 859-861.

29 A. E. Kuznetsov, A. I. Boldyrev, H. J. Zhai, X. Li and L. S. Wang, J. Am. Chem. Soc., 2002, 124, 11791-11801.

30 A. E. Kuznetsov and A. I. Boldyrev, Struct. Chem., 2002, 13, 141-148.

31 A. I. Boldyrev and L. S. Wang, Chem. Rev., 2005, 105, 37163757.

32 N. He, H. B. Xie and Y. H. Ding, Microporous Mesoporous Mater., 2010, 130, 67-75.

33 J. M. Mercero, E. Matito, F. Ruipérez, I. Infante, X. Lopez and J. M. Ugalde, Chem.-Eur. J., 2015, 21, 9610-9614.

34 C.-G. Zhan, F. Zheng and D. A. Dixon, J. Am. Chem. Soc., 2002, 124, 14795-14803.

35 D. E. Bergeron, A. W. Castleman, T. Morisato and S. N. Khanna, Science, 2004, 304, 84-87. 
36 D. E. Bergeron, P. J. Roach, A. W. Castleman, N. Jones and S. N. Khanna, Science, 2005, 307, 231-235.

37 J. U. Reveles, S. N. Khanna, P. J. Roach and A. W. Castleman Jr, Proc. Natl. Acad. Sci. U. S. A., 2006, 103, 18405-18410.

38 W.-M. Sun, D. Wu, X.-H. Li, Y. Li, J.-H. Chen, C.-Y. Li, J.-Y. Liu and Z.-R. Li, J. Phys. Chem. C, 2016, 120, 2464-2471.

39 J. Reveles, T. Baruah and R. R. Zope, J. Phys. Chem. C, 2015, 119, 5129-5137.

40 S. R. Miller, N. E. Schultz, D. G. Truhlar and D. G. Leopold, J. Chem. Phys., 2009, 130, 024304.

41 B. K. Rao and P. Jena, J. Chem. Phys., 2000, 113, 1508-1513.

42 J. Sun, W. C. Lu, H. Wang, Z.-S. Li and C.-C. Sun, J. Phys. Chem. A, 2006, 110, 2729-2738.

43 M. D. Deshpande and D. G. Kanhere, Phys. Rev. B, 2003, 68, 035428.

44 L. G. M. Pettersson, C. W. Bauschlicher Jr and T. Halicioglu, J. Chem. Phys., 1987, 87, 2205-2213.

45 P. P. Bera, K. W. Sattelmeyer, M. Saunders, H. F. Schaefer and P. v. R. Schleyer, J. Phys. Chem. A, 2006, 110, 4287-4290.

46 J. Tong, Y. Li, D. Wu, Z.-R. Li and X.-R. Huang, J. Phys. Chem. A, 2010, 115, 2041-2046.

47 M. Saunders, J. Comput. Chem., 2004, 25, 621-626.

48 C. Moller and M. S. Plesset, Phys. Rev., 1934, 46, 618-622.

49 A. E. Reed, R. B. Weinstock and F. J. Weinhold, J. Chem. Phys., 1985, 83, 735-746.

50 U. Kock and P. L. A. Popelier, J. Phys. Chem., 1995, 99, 97479754.

51 P. L. A. Popelier, J. Phys. Chem. A, 1998, 102, 1873-1878.

52 P. v. R. Schleyer, C. Maerker, A. Dransfeld, H. Jiao and N. J. v. E. Hommes, J. Am. Chem. Soc., 1996, 118, 6317-6318.

53 F. Ma, R. Y. Li, Z. R. Li, M. M. Chen, H. L. Xu, Z. J. Li, D. Wu and Z. S. Li, J. Mol. Struct.: THEOCHEM, 2009, 913, 80-84.

54 S. F. Boys and F. Bernardi, Mol. Phys., 1970, 19, 553-566.

55 I. Alkorta and J. Elguero, J. Phys. Chem. A, 1999, 103, 272-279.
56 M. J. Frisch, G. W. Trucks, H. B. Schlegel, G. E. Scuseria, M. A. Robb, J. R. Cheeseman, G. Scalmani, V. Barone, B. Mennucci, G. A. Petersson, H. Nakatsuji, M. Caricato, X. Li, H. P. Hratchian, A. F. Izmaylov, J. Bloino, G. Zheng, J. L. Sonnenberg, M. Hada, M. Ehara, K. Toyota, R. Fukuda, J. Hasegawa, M. Ishida, T. Nakajima, Y. Honda, O. Kitao, H. Nakai, T. Vreven, J. A. Montgomery Jr, J. E. Peralta, F. Ogliaro, M. Bearpark, J. J. Heyd, E. Brothers, K. N. Kudin, V. N. Staroverov, R. Kobayashi, J. Normand, K. Raghavachari, A. Rendell, J. C. Burant, S. S. Iyengar, J. Tomasi, M. Coss, N. Rega, J. M. Millam, M. Klene, J. E. Knox, J. B. Cross, V. Bakken, C. Adamo, J. Jaramillo, R. Gomperts, R. E. Stratmann, O. Yazyev, A. J. Austin, R. Cammi, C. Pomelli, J. W. Ochterski, R. L. Martin, K. Morokuma, V. G. Zakrzewski, G. A. Voth, P. Salvador, J. J. Dannenberg, S. Dapprich, A. D. Daniels, O. Farkas, J. B. Foresman, J. V. Ortiz, J. Cioslowski and D. J. Fox, GAUSSIAN 09, Gaussian, Inc., Wallingford CT, 2009.

57 R. Dennington, K. Todd, J. Millam, K. Eppinnett, W. L. Hovell and R. Gilliland, GaussView, version 3.09 edn, Semichem, Inc, Shawnee Mission, KS, 2003.

58 W.-M. Sun, Y. Li, D. Wu and Z.-R. Li, Phys. Chem. Chem. Phys., 2012, 14, 16467-16475.

59 R. G. Parr and R. G. Pearson, J. Am. Chem. Soc., 1983, 105, 7512-7516.

60 T. Zhao, Q. Wang and P. Jena, Nanoscale, 2017, 9, 4891-4897. 61 W. Ekardt, Phys. Rev. B, 1984, 29, 1558.

62 W.-D. Knight, K. Clemenger, W. A. de Heer, W. A. Saunders, M. Chou and M. L. Cohen, Phys. Rev. Lett., 1984, 52, 2141.

63 S. Miertuš, E. Scrocco and J. Tomasi, Chem. Phys., 1981, 55, 117-129.

64 S. Miertus and J. Tomasi, Chem. Phys., 1982, 65, 239-245.

65 F. F. Wang, Z. R. Li, D. Wu, X. Y. Sun, W. Chen, Y. Li and

C. C. Sun, ChemPhysChem, 2006, 7, 1136-1141. 